\title{
Low-Frequency Variability of the Yellow Sea Cold Water Mass Identified from the China Coastal Waters and Adjacent Seas Reanalysis
}

\author{
Xuewei Li, ${ }^{1}$ Xidong Wang, ${ }^{2}$ Peter C. Chu, ${ }^{3}$ and Dongliang Zhao ${ }^{1}$ \\ ${ }^{1}$ Physical Oceanography Laboratory, Ocean University of China, 238 Songling Road, Qingdao 266100, China \\ ${ }^{2}$ Key Laboratory of Marine Environment Information Technology, SOA, National Marine Data and Information Service, \\ Tianjin 300171, China \\ ${ }^{3}$ Naval Ocean Analysis and Prediction Laboratory, Department of Oceanography, Naval Postgraduate School, Monterey, \\ CA 93943, USA
}

Correspondence should be addressed to Xidong Wang; xidong_wang@yahoo.com

Received 19 December 2014; Revised 26 March 2015; Accepted 17 April 2015

Academic Editor: Juan Jose Ruiz

Copyright (C) 2015 Xuewei Li et al. This is an open access article distributed under the Creative Commons Attribution License, which permits unrestricted use, distribution, and reproduction in any medium, provided the original work is properly cited.

\begin{abstract}
This study uses the China Coastal Waters and Adjacent Seas Reanalysis (CORA) data to investigate the interannual and decadal variability of the Yellow Sea cold water mass (YSCWM) and its relationship to climate indices including the Arctic Oscillation (AO), El Niño/Southern Oscillation (ENSO), and Pacific Decadal Oscillation (PDO). On the interannual timescale, the strong correlation between winter PDO and the YSCWM may indicate the dominant effect of winter PDO on the YSCWM through the modulation of local heat flux and wind stress. It is also found that the local wind stress and heat flux in summer have little impact on the interannual variability of the YSCWM. On the decadal time scale, the YSCWM is associated with winter AO and winter PDO. Winter AO mainly controls local heat flux, modulating the decadal variability of the YSCWM. In contrast, winter PDO is strongly connected with winter heat flux and wind stress to modulate the decadal variability of the YSCWM. In summer, for three climate factors, ENSO is the dominant factor controlling the decadal variability of the YSCWM.
\end{abstract}

\section{Introduction}

The Yellow Sea is a semienclosed marginal sea of the Pacific Ocean, bordered by the Chinese mainland to the west, the Korean Peninsula to the east, and the Bohai Bay to the north. Several rivers drain into the Yellow Sea and provide a lot of nutrients. The Yellow Sea covers an area of roughly $400,000 \mathrm{~km}^{2}$ and it is mostly shallower than $80 \mathrm{~m}$ (Figure 1). The central trough extends from southeast to north with an average depth of $44 \mathrm{~m}$ [1].

The seasonal variation is evident in the circulation and hydrographical characteristics of the Yellow Sea. In winter, strong vertical mixing due to strong winds and surface heat fluxes produce a uniform and cold vertical temperature profile. In summer, the solar radiation increases and rapidly warms the upper layer of the Yellow Sea. Therefore, the seasonal thermocline rapidly forms and locates at $10-30 \mathrm{~m}$ depth. Due to the combined topographic, dynamic, and thermodynamic effects, there is a remnant of cold water $\left(<10^{\circ} \mathrm{C}\right)$ under the seasonal thermocline in the central trough of the Yellow Sea which is referred as Yellow Sea Cold Water Mass (YSCWM) and is present throughout the whole summer season occupying almost $30 \%$ of the Yellow Sea area, thus becoming one of the most important characteristics of the Yellow Sea. The YSCWM has an important effect on the hydrographic features and the phytoplankton biomass and production in the Yellow Sea [2-5].

He et al. [6] first studied the formation and properties of the YSCWM and identified that the water mass locally formed during the previous winter by the sea surface cooling and strong vertical mixing. Su [7] found that the bottom cold water in northern Yellow Sea is influenced by coastal water and then moves southward in winter, mixing with highsalinity water from the open ocean. The bottom cold water in 


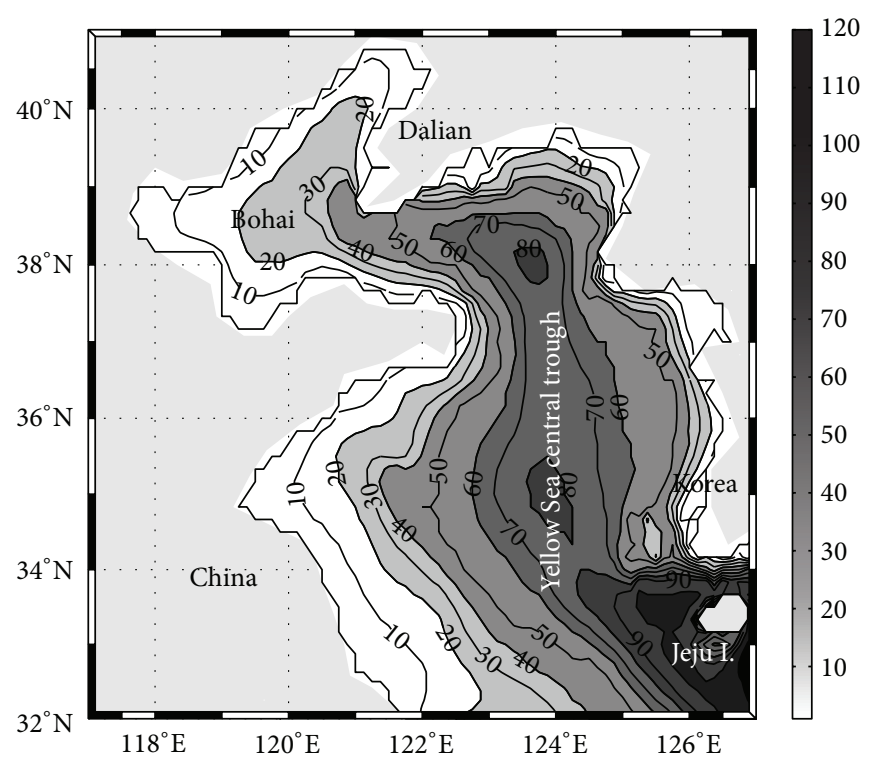

Figure 1: Bottom topography of the Yellow Sea (m).

northern Yellow Sea remains at the bottom in summer, and it is influenced by the Yellow Sea Coastal Water [8]. Since 1990, numerical models are used to investigate the mechanism of the YSCWM formation and its associated circulation [9-13]. Su and Huang [9], using qualitative analysis and numerical simulations, obtained that the vertical circulation is characterized by a double cell structure. Miu et al. [10, 11] used a model to explain the formation of the YSCWM and basic characteristics of density circulation based on the fluid dynamics and the thermodynamics. Recently, several studies were conducted to investigate the characteristics of the YSCWM using temperature and salinity observation. Jiang et al. [14] studied its thermohaline characteristics based on the temperature and salinity data observed by the State Oceanic Administration People's Republic of China from 1976 to 1999 . Hu and Wang [15] used empirical orthogonal function to investigate the interannual variability with temperature data collected in August from 1975 to 2003. Although previous studies investigated the interannual variability of the YSCWM through some frequently measured temperature sections, due to the lack of a long and regional observational record they could not describe the interannual and decadal variability at a regional scale. However, ocean reanalysis data has a better space-time coverage, which allows us to investigate the whole features of the YSCWM and its response to climate variability. Because the YSCWM is the most conservative among water masses in the Yellow Sea, it may contain clearer climate signals than any other water masses in the Yellow Sea. These long-term signals are important to understand the climatological evolution of the Yellow Sea [16].

Therefore, this study aims to characterize the lowfrequency variability of the YSCWM and it possible relationship with three climate indices: the Arctic Oscillation (AO), El Niño/Southern Oscillation (ENSO), and the Pacific Decadal Oscillation (PDO) using the China Coastal Waters and Adjacent Seas Reanalysis (CORA) data. CORA assimilated the in situ observed temperature and salinity profiles collected by the National Marine Data and Information Service People's Republic of China, World Ocean Data 2005 (WOD05), Global Temperature and Salinity Profile Project (GTSPP), and Array for Real-Time Geostrophic Oceanography (Argo) floats. It is worthy to emphasize that the dataset from the National Marine Data and Information Service People's Republic of China integrates almost all the available historical observed temperature-salinity profiles in the Yellow Sea, which contributes to the high quality of CORA in the Yellow Sea. CORA has been validated using independent observations in previous studies. The results showed that CORA can better simulate temperature-salinity structure, mesoscale, and large-scale circulation in the western north Pacific including the Yellow Sea [17]. For further details about CORA and the assimilated observations the reader is referred to [17].

The rest of the paper is organized as follows. In Section 2, we describe the data used in this study. In Section 3, we explore the seasonal evolution and formation of the YSCWM. In Section 4, we investigate the interannual and decadal variability of the YSCWM and discuss the relationship between the YSCWM and the three climate indices (AO, ENSO, and PDO) considered in this study. Section 5 gives a brief summary and discussion.

\section{Data and Methods}

The CORA covers a period of 51 years from January 1958 to December 2008 . The domain ranges from $99^{\circ} \mathrm{E}$ to $150^{\circ} \mathrm{E}$ and from $10^{\circ} \mathrm{S}$ to $52^{\circ} \mathrm{N}$, including the Bohai Sea, the Yellow Sea, the East China Sea, the South China Sea, and adjacent seas. The datasets consist of monthly mean fields with horizontal resolution of $0.25^{\circ}$ and 35 vertical depth levels. 

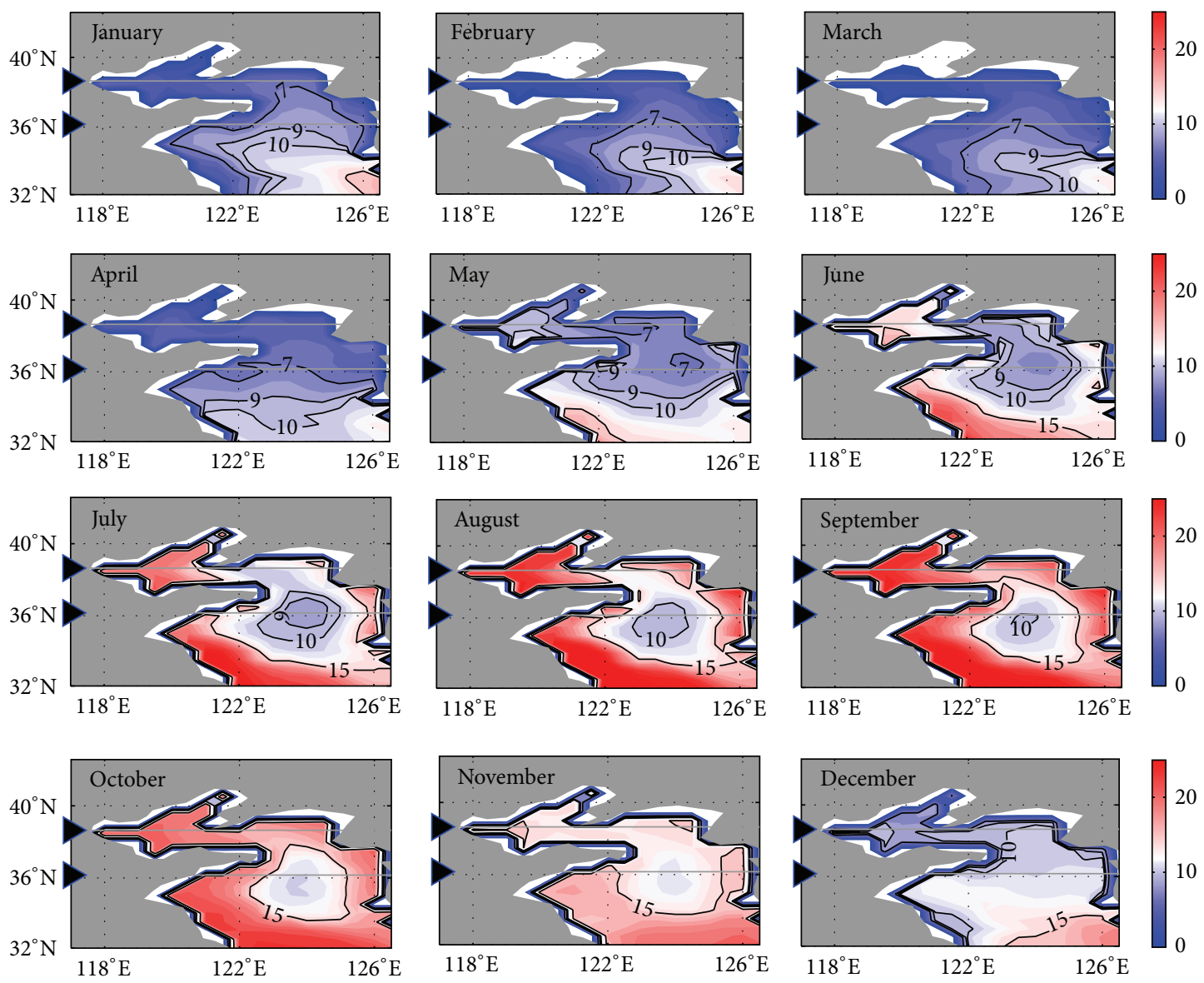

FIGURE 2: Monthly mean climatology of bottom water temperature $\left({ }^{\circ} \mathrm{C}\right)$ in the Yellow Sea. The triangles indicate the location where the cross sections are performed.

To examine what climate factors are associated with the YSCWM variability, three climate indices are selected: AO index [18], Multivariable ENSO index (MEI) [19, 20], and PDO index [21, 22]. $\mathrm{AO}$ is the dominant pattern of nonseasonal sea level pressure variability north of $20^{\circ} \mathrm{N}$. It is characterized by sea level pressure anomalies with opposite signs in the Arctic and $37-45^{\circ} \mathrm{N}$ [18]. MEI is an average of the main ENSO features contained in six observed variables over the tropical Pacific. A positive (negative) value of the MEI indicates the warm (cold) ENSO phase $[19,20]$. The PDO index is defined as the leading principal component of monthly sea surface temperature variability north of $20^{\circ} \mathrm{N}$ in the North Pacific, and it is a long-lived El Niño-like pattern of the Pacific climate variability $[21,22]$.

The monthly mean wind stress and net heat flux are computed averaging the daily values obtained from the NCEP-NCAR reanalysis with the resolution of $2.5^{\circ}$ [23]. The period of 51 years ranging from January 1958 to December 2008 is used to investigate the mechanisms of the YSCWM variability associated with $\mathrm{AO}, \mathrm{ENSO}$, and PDO. To examine the interannual and decadal variability of the YSCWM, all-time series used in this study are separated into two components including interannual and decadal variability. The decadal component is obtained by applying a 7-year Gaussian filter to the original time series. The interannual component is obtained by subtracting the decadal component from the original time series. To extract the dominant mode of heat flux and wind stress in the Yellow Sea's region, an empirical orthogonal (EOF) analysis is performed upon the interannual and decadal time series.

\section{Seasonal Evolution and Formation of the YSCWM}

The YSCWM can be clearly distinguished in the bottom of the Yellow Sea. The Yellow Sea bottom water is the most stable level of the YSCWM [6]. YSCWM is traditionally defined as the cold water lower than $10^{\circ} \mathrm{C}$ in the bottom of the Yellow Sea in summer [6]. Thus, climatological monthly averaged temperature of the Yellow Sea bottom water during 19582008 is used to examine the formation and evolution of the YSCWM (Figure 2).

In winter (December-February), the temperature is gradually reduced in the Yellow Sea. The cold water area (with temperatures below $10^{\circ} \mathrm{C}$ ) is gradually increased. In January, there is a tongue of warmer water (with temperatures warmer than $\left.10^{\circ} \mathrm{C}\right)$ whose tip moves from $\left(35^{\circ} \mathrm{N}, 122.5^{\circ} \mathrm{E}\right)$ to $\left(34^{\circ} \mathrm{N}\right.$, $123^{\circ} \mathrm{E}$ ) from January to February and further moves southeastward in spring (Figure 2). The temperature in the central trough is higher than that of the surrounding water in winter. 

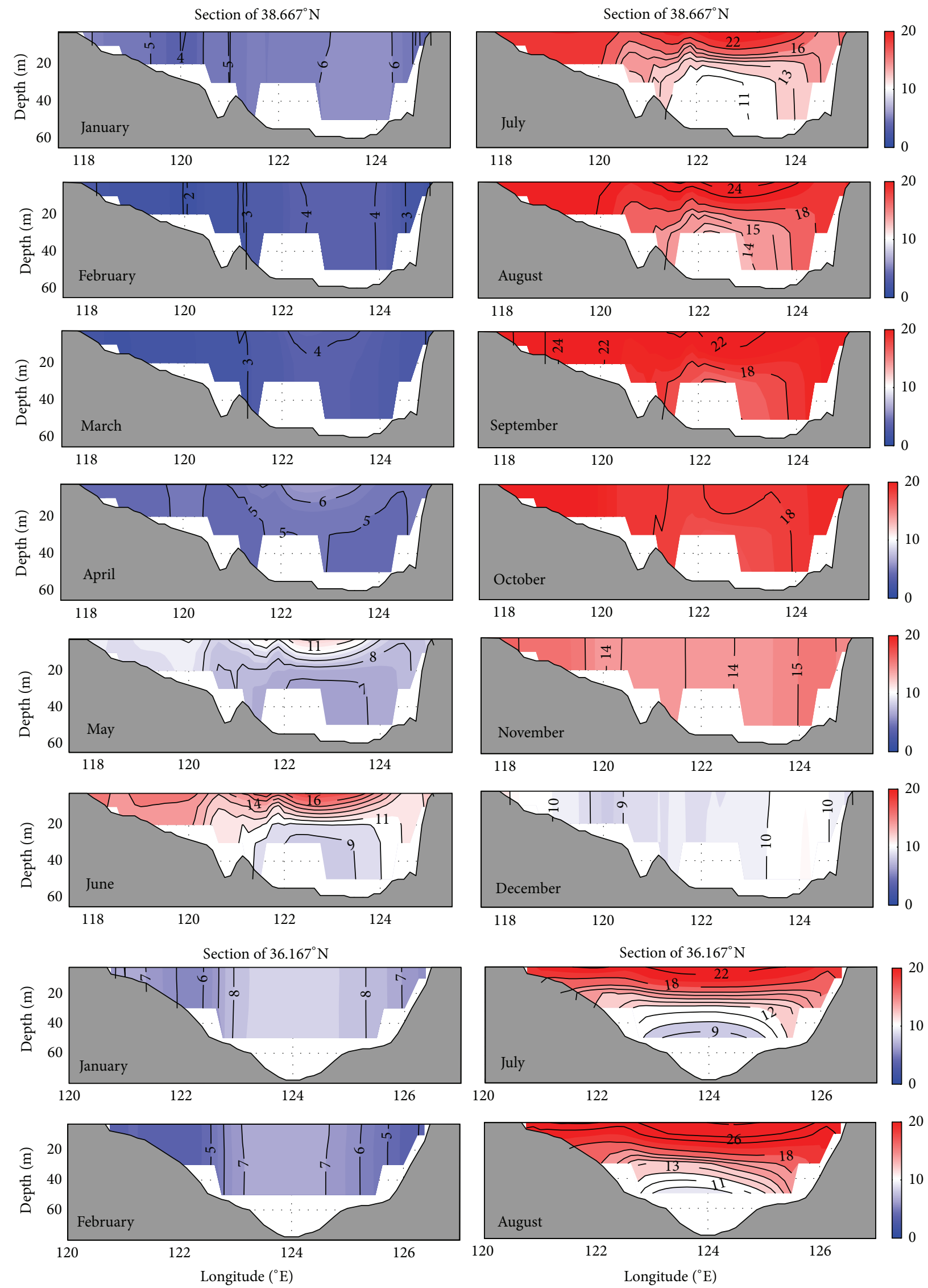

Figure 3: Continued. 

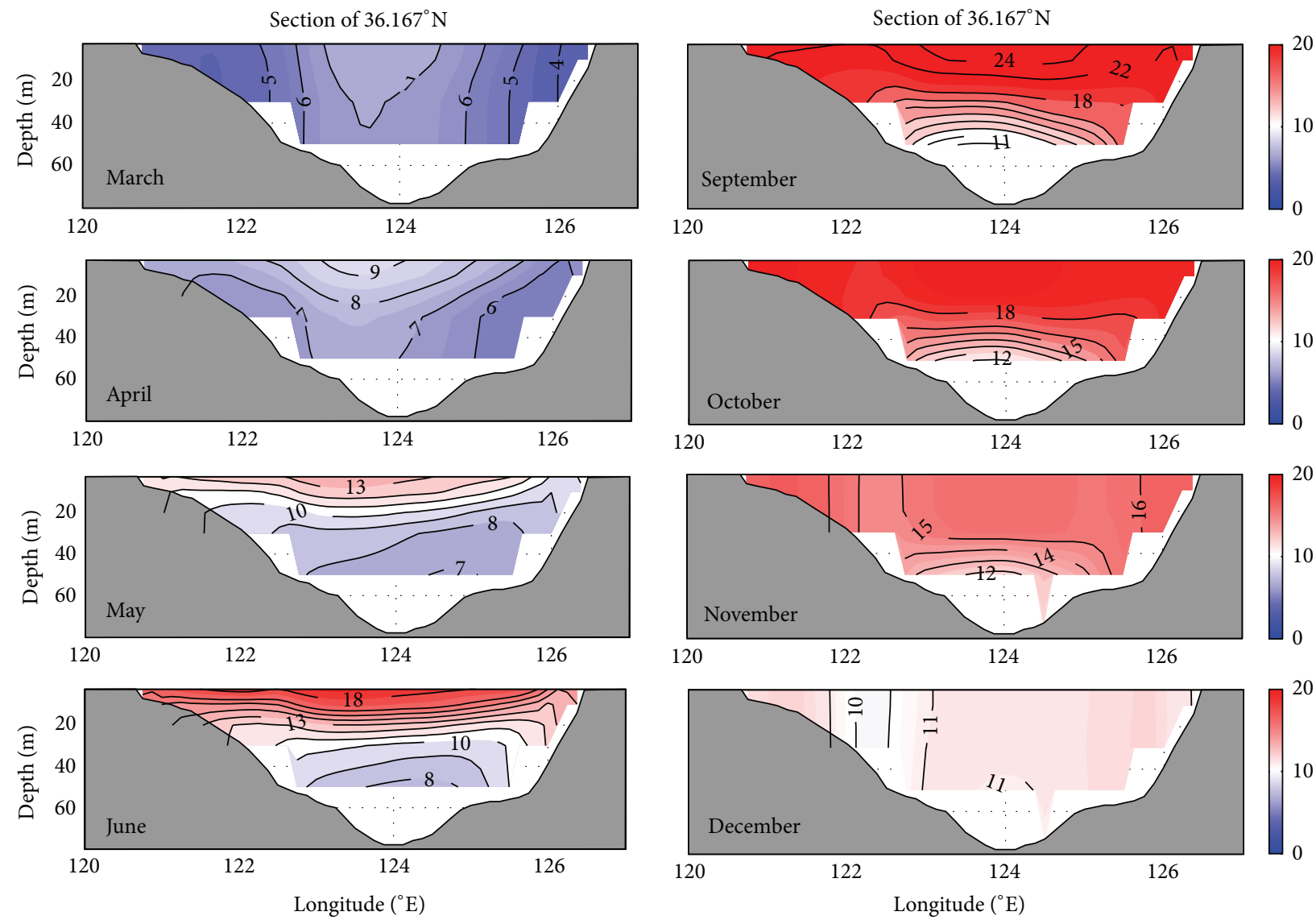

Figure 3: Vertical cross sections of monthly mean temperature $\left({ }^{\circ} \mathrm{C}\right)$ along $36.17^{\circ} \mathrm{N}$ and $38.667^{\circ} \mathrm{N}$ for the locations indicated in Figure 2.

In spring (March-May), the Yellow Sea water is warming further, and its frontal structure is changing. In March, the temperature structure is similar to that in February. The warm water tough still exists and then gradually disappears in April. However, in May, there are three cold water patches with temperatures below $7^{\circ} \mathrm{C}$ form around $36^{\circ} 25^{\prime} \mathrm{N}, 122.5^{\circ} \mathrm{E}, 35^{\circ}$ $50^{\prime} \mathrm{N}, 123.5^{\circ} \mathrm{E}$, and $36^{\circ} 25^{\prime} \mathrm{N}, 125^{\circ} \mathrm{E}$ (Figure 2). This suggests that the YSCWM has started to form in the Yellow Sea.

In summer (June-August), the cold center gradually enhances. In June, the cold center located at $36^{\circ} 25^{\prime} \mathrm{N}, 122.5^{\circ} \mathrm{E}$ starts to move eastward, while the other two cold water centers merge into one during June, suggesting that the main body of the YSCWM begins to form over southern Yellow Sea. The cold water mass in the bottom of the central trough has a shape that resembles a saddle. In July, the cold water that has a temperature lower than $10^{\circ} \mathrm{C}$ covers a third of the Yellow Sea's total area. Compared with that in the late spring, the isotherm of $10^{\circ} \mathrm{C}$ expands southward from $36^{\circ} \mathrm{N}$ to $35.25^{\circ} \mathrm{N}$ (Figure 2). This indicates that the YSCWM has reached it maximum extension.

In autumn (September-November), the temperature of the coastal water drops, especially in northern Yellow Sea. Although the YSCWM is still visible until November, the lowest temperature at its center is around $12^{\circ} \mathrm{C}$, and its area has also reduced. In December, the YSCWM has completely disappeared.
We have analyzed the formation and evolution of the YSCWM through the horizontal distribution of temperature at the Yellow Sea bottom. Next, we choose two vertical temperature sections of the YSCWM across southern and northern Yellow Sea, respectively. The location of the two sections is indicated with triangles in Figure 2. We will further explore the formation and the evolution mechanism of the YSCWM by analyzing the vertical structure of temperature in different seasons.

Over northern Yellow Sea, the cross section is performed at $38.66^{\circ} \mathrm{N}$ through the center of the YSCWM. As shown in Figure 3, in winter, the water column is completely uniform. In April, the enhanced solar radiation, the weaker convection, and mixing destroy the vertical uniform distribution of temperature, and a thermocline is formed due to water stratification. But this thermocline is weak with a maximum gradient of $\sim 0.2^{\circ} \mathrm{C} / \mathrm{m}$ at approximately $10 \mathrm{~m}$ depth. In May, the thermocline develops rapidly, and its intensity is greater than $0.3^{\circ} \mathrm{C} / \mathrm{m}$ at approximately $15 \mathrm{~m}$ depth. At the same time, an area with temperatures under $8^{\circ} \mathrm{C}$ forms underneath $20 \mathrm{~m}$ with minimum temperatures under $7^{\circ} \mathrm{C}$ near $38.667^{\circ} \mathrm{N}, 123^{\circ} \mathrm{E}$. This cold center is also visible in Figure 2. The YSCWM has started to form at the bottom in May.

In early summer, the stratification at depths between 10 and $20 \mathrm{~m}$ became evident, and the thermocline becomes stable. The temperature profile presents a three-layer structure: 


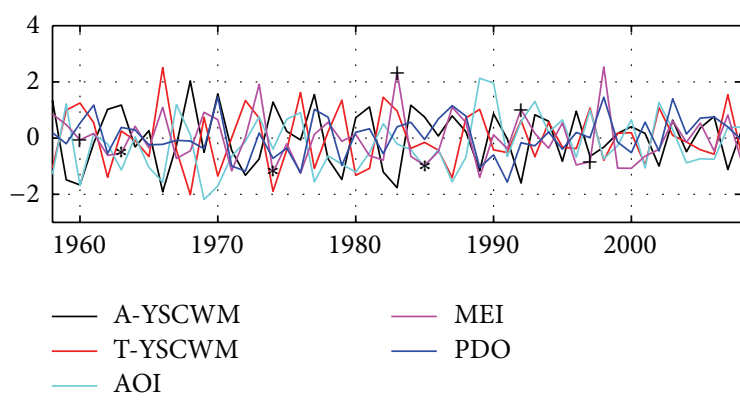

(a)

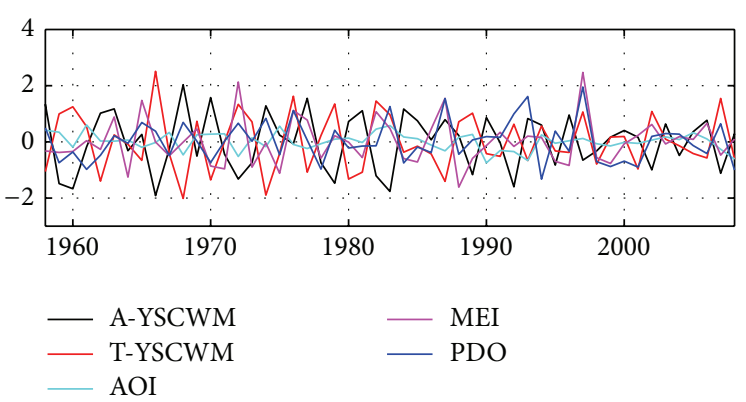

(b)

FIGURE 4: Interannual time series of (a) winter AO, MEI, and PDO indices, and A-YSCWM and T-YSCWM in August (b) summer AO, ENSO, PDO, and the A-YSCWM and T-YSCWM in August. Time series of the A-YSCWM and T-YSCWM are standardized. The A-YSCWM and T-YSCWM represent the area and averaged temperature of the YSCWM, respectively. The "+" represents the El Niño events, and the "*" represents the La Niña events.

the upper mixed layer contains warm water; the thermocline has sharp temperature gradient $\left(0.2-0.5^{\circ} \mathrm{C} / \mathrm{m}\right)$; and the lower layer contains cold water which is nearly uniform. In midsummer, the sea surface temperature rises rapidly, and the strength of thermocline reaches its maximum, which is as high as $1.0^{\circ} \mathrm{C} / \mathrm{m}$. At the same time, the bottom water still has temperatures below $10^{\circ} \mathrm{C}$. In autumn, the temperature of the cold center rises from $8^{\circ} \mathrm{C}$ to $11^{\circ} \mathrm{C}$ (Figure 2). This indicates that the YSCWM is gradually decaying. In November, the thermocline disappears completely, and the YSCWM is also gone.

We choose the section at $36.167^{\circ} \mathrm{N}$ to examine evolution of the YSCWM in southern Yellow Sea (Figure 3). The evolution process of the thermocline in the southern Yellow Sea is similar to the northern Yellow Sea, but due to the different geographical position, topography, and tidal mixing intensity, their vertical structures are different. In spring, as the temperature increases near the coast, the thermocline weakens on both coasts of the southern Yellow Sea, and the area of the cold water increases. In May, with the increasing temperature and enhancing thermocline, three-layer structure occurs. The westward moving of the east cold center makes cold water only exists in the central trough. In June-August, the temperature of the bottom water in the central trough is less than $10^{\circ} \mathrm{C}$. In October, the thermocline only exists at the central deeper water area than $30 \mathrm{~m}$. The intensity of thermocline also reduces significantly. By December, the thermocline completely disappears, and the YSCWM is also gone.

There are two cold centers below the thermocline located at $122.5^{\circ} \mathrm{E}$ and $124.5^{\circ} \mathrm{E}$ in the southern Yellow Sea in April, which are different at the northern Yellow Sea (Figure 3). This difference is due to the influence of the Yellow Sea warm current. In winter, a warm tongue from west of the Jeju Island stretches northward along the central trough (Figure 2), which causes the temperature over the central part to be higher than that over the two coasts of the Yellow Sea. For example, in the cross section performed at $36.167^{\circ} \mathrm{N}$, the temperature in the central part of the southern Yellow Sea is $7^{\circ} \mathrm{C}$ in February. However, the temperature on both coasts is $4 \sim 6^{\circ} \mathrm{C}$. In April, the temperature over the central region is greater than $8^{\circ} \mathrm{C}$, but the temperature on both coasts is $6 \sim 7^{\circ} \mathrm{C}$
(Figure 3). The bottom temperature in the southern Yellow Sea has two cold centers on both flanks of central trough from January to April (Figure 3).

\section{Interannual and Decadal Variability of the YSCWM}

The YSCWM is a large water mass covering a third of the bottom layer at its largest extension. It has relatively stable properties with low temperature and high salinity. However, due to the influence of external forcings such as wind stress and heat fluxes, the thermohaline structure within the water mass may change. The YSCWM is traditionally defined as the cold water lower than $10^{\circ} \mathrm{C}$ in the bottom of the Yellow Sea in summer [6]. To investigate the interannual and decadal variability of the YSCWM, we define the YSCWM as the bottom water colder than $10^{\circ} \mathrm{C}$. To examine the effects of the different seasonal climate forcings on the interannual and decadal variability of the YSCWM, winter (summer) climate indices averaged from December to February (July to September) are used.

\subsection{Interannual Variability}

4.1.1. Relationship to the Climate Forcings in Winter. On the interannual time scale, both winter $\mathrm{AO}$ and ENSO indices are negatively (positively) correlated with the area and averaged temperature of the YSCWM (hereafter referred to as AYSCWM and T-YSCWM, resp.). Although the correlation coefficients are low, it is clearly shown that El Niño events (e.g., 1960, 1983, 1992, and 1997) correspond to smaller AYSCWM and higher T-YSCWM, while La Niña $(1963,1974$, 1985 ) events correspond to larger A-YSCWM and lower TYSCWM (Figure 4(a) and Table 1). The correlation between the winter PDO index and A-YSCWM (T-YSCWM) is positive (negative) and statistically significant at the confidence level of 95\%. The correlation between the winter PDO index and the YSCWM is the strongest among all of the three climatic indices, which may indicate that the effect of winter $\mathrm{PDO}$ on the YSCWM is the dominant climate forcings (Figure 4(a) and Table 1). 


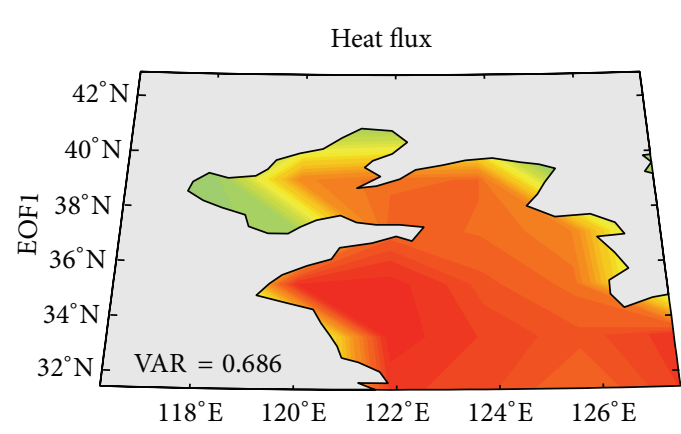

(a)

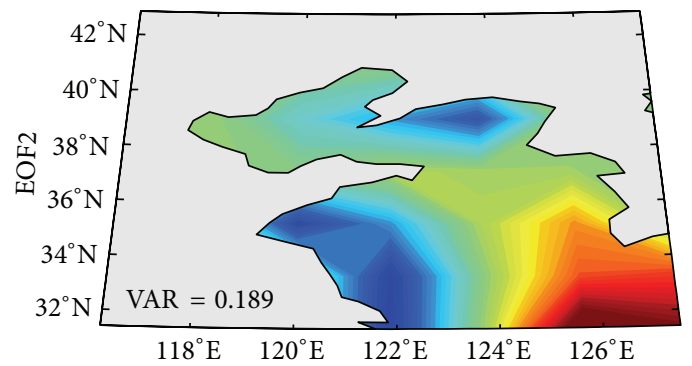

(c)

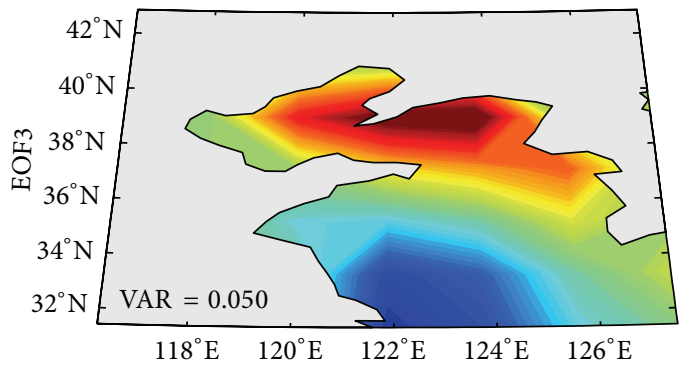

(e)
Winter

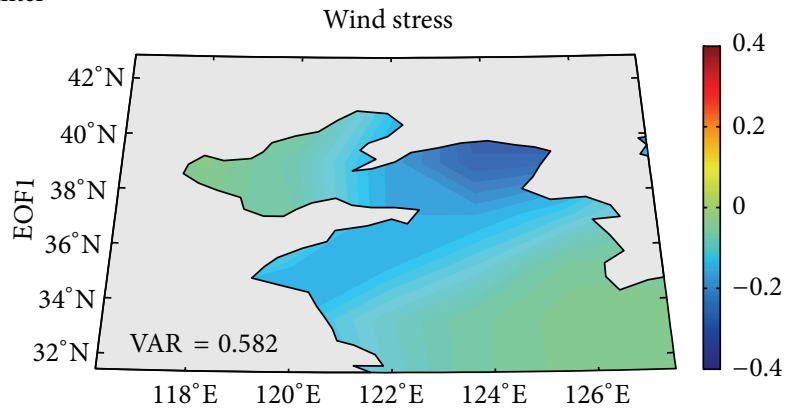

(b)

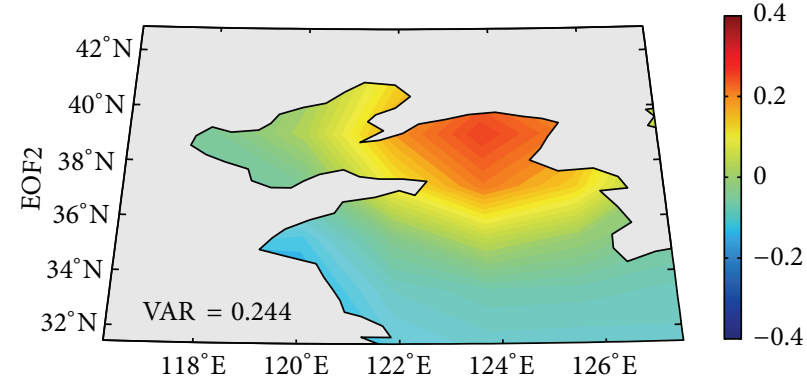

(d)

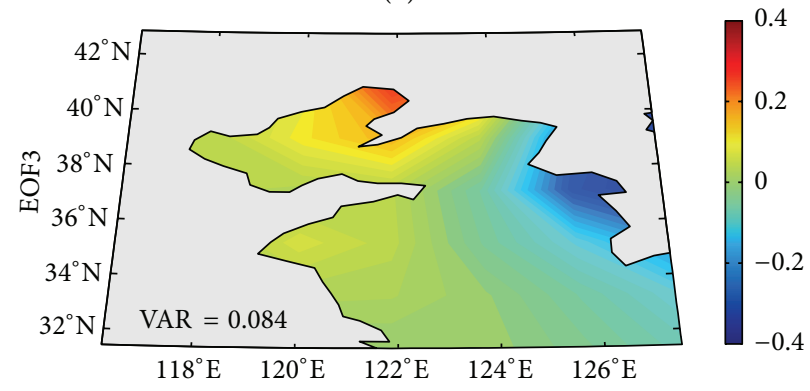

(f)

Figure 5: EOF1, EOF2, and EOF3 of interannual component for winter heat flux ((a), (c), and (e)) and winter wind stress ((b), (d), and (f)). Positive values indicate that heat is transferred from the ocean to the atmosphere.

To explore how the local thermal and wind forcing affect the interannual variability of the YSCWM, the interannual components of winter heat flux and wind stress are decomposed using EOFs (Figure 5). EOF1 of winter heat flux shows a positive loading over the total Yellow Sea, which explains $68.6 \%$ of the total variance (Figure $5(a)$ ). The EOF2 of winter heat flux represents an east-west dipole structure, with positive loading in the east and negative loading in the west (Figure 5(c)). The EOF3 has a south-north dipole structure with positive loading in the northern Yellow Sea and negative loading in the southern Yellow Sea (Figure 5(e)). EOF1 of winter wind stress is characterized by negative values over almost the whole Yellow Sea, which account for $58.2 \%$ of the total variance (Figure 5(b)). The EOF2 of winter wind stress reveals a south-north dipole pattern with positive values in the northern Yellow Sea and negative values in the southern Yellow Sea (Figure 5(d)). The EOF3 exhibits a meridional alternate pattern with positive loading in the
Chinese coast and negative loading in the Korean coast (Figure $5(f))$.

The EOF1 of winter heat flux is negatively (positive) correlated with the A-YSCWM (T-YSCWM) (Figure 6(a) and Table 2). This suggests that strong winter heat loss from ocean to atmosphere in the Yellow Sea can induce large A-YSCWM and low T-YSCWM. EOF1 and EOF3 of winter wind stress evidently affect the features of the YSCWM (Figure 6(c) and Table 3). It is shown that both EOF1 and EOF3 of winter wind stress are negatively (positively) correlated with A-YSCWM (T-YSCWM). This indicates that enhanced winter winds over the Yellow Sea tend to make A-YSCWM (T-YSCWM) increase (decrease) (Figure 5(a)).

Figures $7(\mathrm{a})$ and $7(\mathrm{c})$ show the interannual time series of winter $\mathrm{AO}, \mathrm{MEI}$, and PDO indices, as well as the EOF1, $\mathrm{EOF} 2$, and EOF3 of heat flux and wind stress. Only the winter $\mathrm{AO}$ index is positively correlated with the EOF3 of winter heat flux (Table 4). The variations of local winter heat flux 


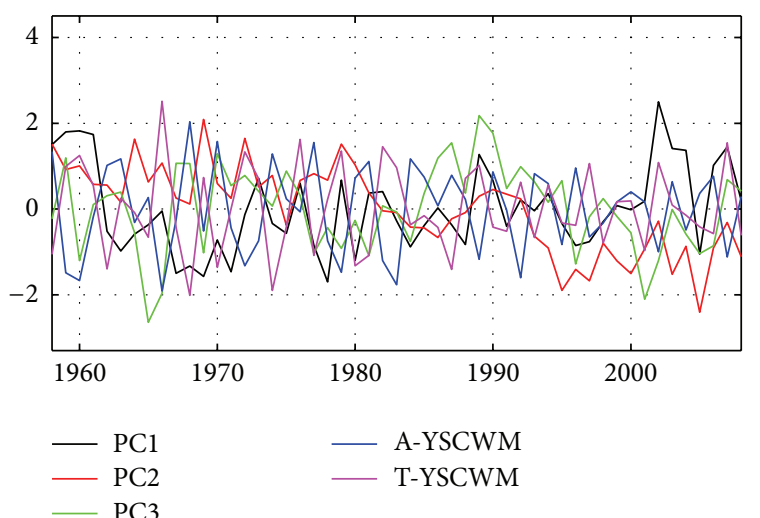

(a)

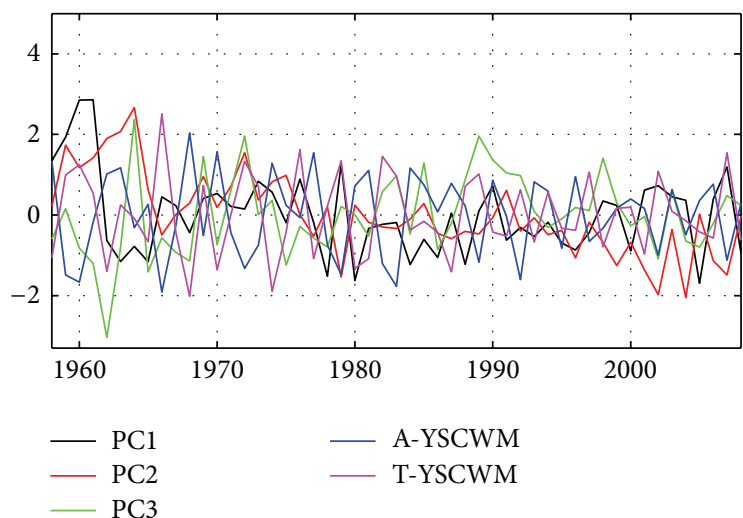

(c)

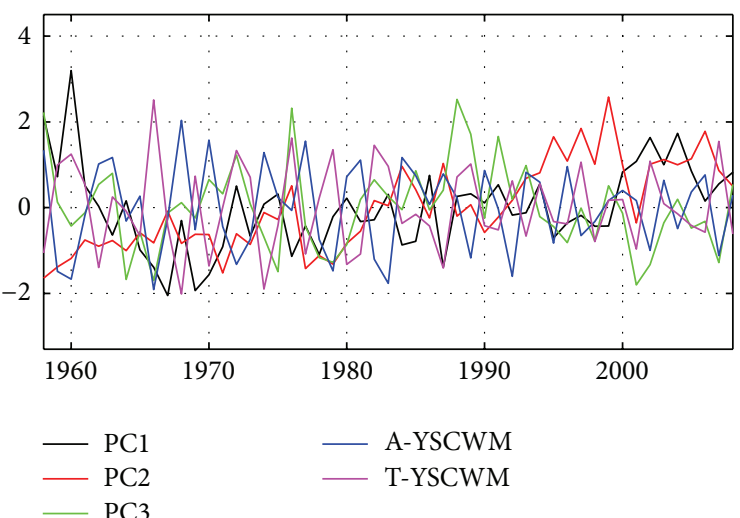

(b)

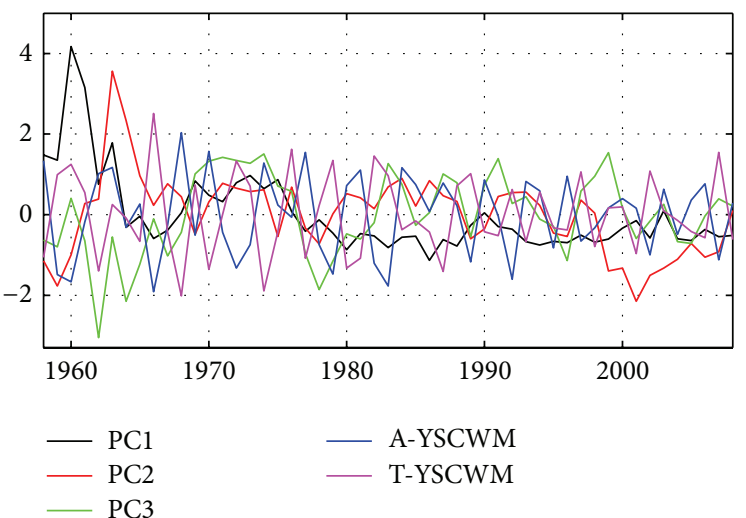

(d)

FIGURE 6: Interannual time series of (a) EOF1, EOF2, and EOF3 of winter heat flux, and the A-YSCWM and T-YSCWM in August (b) EOF1, EOF2, and EOF3 of summer heat flux, and the A-YSCWM and T-YSCWM in August (c) EOF1, EOF2, and EOF3 of winter wind stress, and the A-YSCWM and T-YSCWM in August (d) EOF1, EOF2, and EOF3 of summer wind stress, and the A-YSCWM and T-YSCWM in August. All-time series are standardized. The A-YSCWM and T-YSCWM represent the area and averaged temperature of the YSCWM, respectively.

TABLE 1: Correlation coefficients between the AO, MEI, PDO, and the YSCWM area and temperature in August, including the interannual and decadal components in both summer and winter. Values in bold are statistically significant at the $95 \%$ confidence level.

\begin{tabular}{lcc}
\hline & Area & Average temperature \\
\hline \multicolumn{3}{c}{ Interannual variability } \\
Winter AO & $-\mathbf{0 . 2 3}$ & $\mathbf{0 . 2 5}$ \\
Winter MEI & $-\mathbf{0 . 2 7}$ & 0.10 \\
Winter PDO & $\mathbf{0 . 3 1}$ & $-\mathbf{0 . 3 2}$ \\
Summer AO & $-\mathbf{0 . 2 7}$ & $\mathbf{0 . 3 0}$ \\
Summer MEI & -0.08 & 0.14 \\
Summer PDO & -0.15 & 0.12 \\
\hline & Decadal variability & \\
Winter AO & $-\mathbf{0 . 4 9}$ & -0.05 \\
Winter MEI & $-\mathbf{0 . 4 1}$ & $\mathbf{0 . 3 2}$ \\
Winter PDO & $-\mathbf{0 . 4 3}$ & $\mathbf{0 . 3 1}$ \\
Summer AO & $-\mathbf{0 . 2 9}$ & -0.16 \\
Summer MEI & $-\mathbf{0 . 6 1}$ & $\mathbf{0 . 3 8}$ \\
Summer PDO & -0.26 & 0.04 \\
\hline
\end{tabular}

and wind stress are less related to the winter MEI and PDO (Table 4). In other words, the winter MEI and PDO have less influence on the YSCWM through the modulation of the winter heat flux and wind stress.

4.1.2. Relationship to the Climate Forcings in Summer. A positive correlation exists between the summer AO index and T-YSCWM, with a correlation coefficient of 0.30 that is statistically significant at the confidence level of $95 \%$. The correlations between MEI, PDO and A-YSCWM, TYSCWM are low and not statistically significant (Figure 4(b) and Table 1). This suggests that ENSO and PDO may not be the main factors controlling the interannual variability of the YSCWM in summer.

The interannual variability of summer heat flux and wind stress is analyzed using EOFs. Figures 6(b) and 6(d) show the interannual time series of summer AO, MEI, and PDO indices, as well as the EOF1, EOF2, and EOF3 of heat flux and wind stress. The local heat flux and wind stress in summer have little impact on the variability of the YSCWM (Tables 2 and 3). Actually, none of the three climate indices are correlated with the local heat flux and wind stress (Figures 


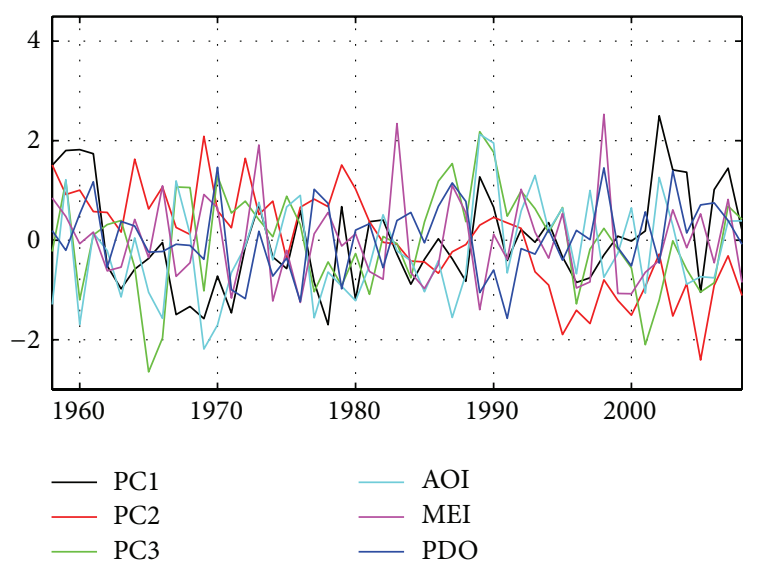

(a)

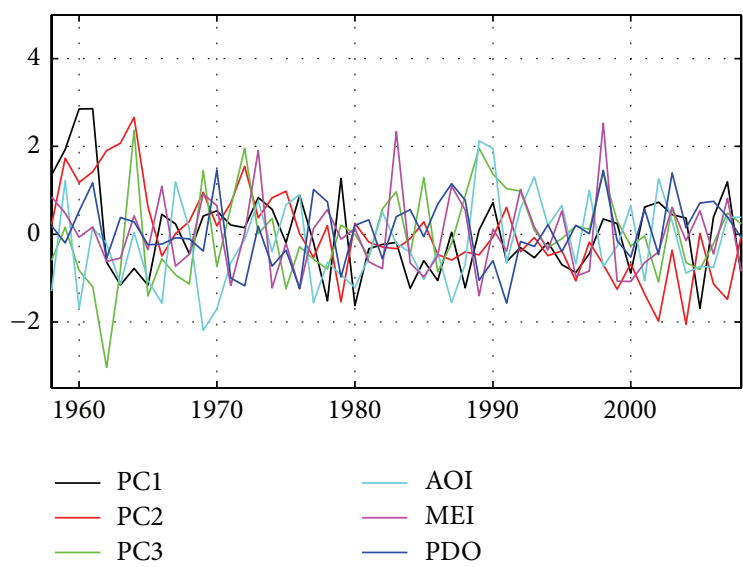

(c)

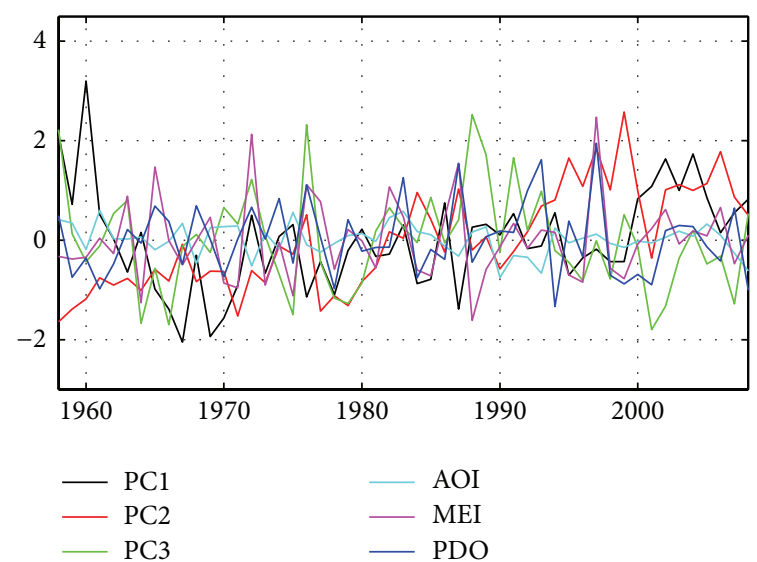

(b)

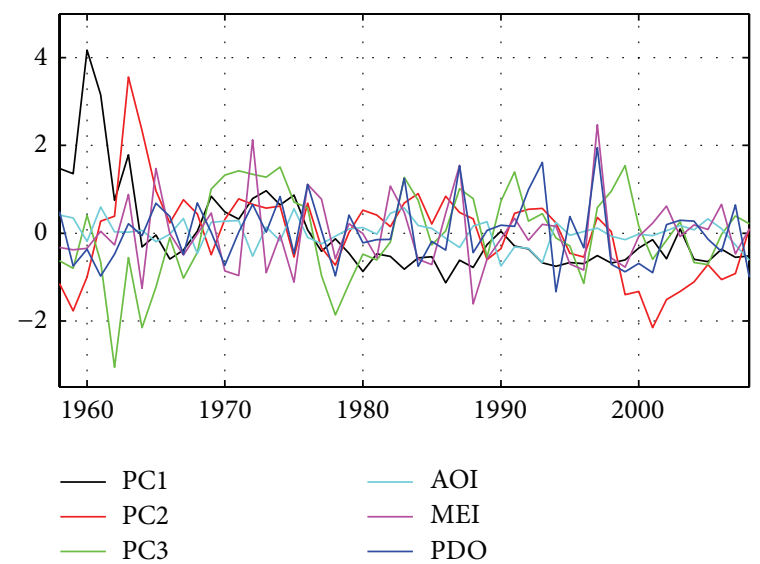

(d)

FIGURE 7: Interannual time series of (a) winter AO, MEI, PDO, EOF1, EOF2, and EOF3 of winter heat flux; (b) summer AO, MEI, PDO, EOF1, EOF2, and EOF3 of summer heat flux; (c) winter AO, ENSO, PDO, EOF1, EOF2, and EOF3 of winter wind stress; (d) summer AO, MEI, and PDO, and EOF1, EOF2, and EOF3 of summer wind stress. EOF1, EOF2, and EOF3 of heat flux and wind stress are standardized.

7(b), 7(d) and Table 5). This means that summer AO, ENSO, and PDO do not affect the YSCWM through modulating the local heat flux and wind stress.

\subsection{Decadal Variability}

4.2.1. Relationship with the Climate Forcings in Winter. The decadal variability of the A-YSCWM has a high correlation with the winter $\mathrm{AO}$ index. The negative correlation between the winter $\mathrm{AO}$ and the area of the YSCWM on the decadal time scale is about -0.49 (Figure $8(\mathrm{a})$ and Table 1). When the winter AO index is in its negative phase during 19581988, A-YSCWM usually has positive anomaly. After 1988, the AO index is continuously positive, and A-YSCWM shows a persistent negative anomaly. When the AO index is in its positive phase, the heat flux loading associated with EOF1 is negative, indicating a net heat flux from the atmosphere and into the ocean. A-YSCWM also reduces accordingly (Figures 9, 11(a) and Table 4).

The PDO index is correlated with A-YSCWM and TYSCWM, with the correlation coefficient of -0.43 and 0.31 , respectively (Figure 8(a) and Table 1), and maintains positive or negative values prevailing for 20-30 year periods [21, 22]. The decadal cycle of the YSCWM also shows a similar feature (Figure $8(\mathrm{a})$ ). In winter, the PDO index has strong links with the Aleutian low. Negative phase of the PDO represents warm anomalies in the extratropical North Pacific [20]. The spatial pattern of the PDO is strongly associated with the EOF1 of heat flux (Figure 10(a)). When the PDO is in its positive phase, the heat flux from atmosphere to ocean is increased in the Yellow Sea, which reduces the A-YSCWM (Figures 9, 11(a) and Table 4). The reverse is true during the negative PDO phase. The PDO also has a connection with EOF2 and EOF3 of the wind stress (Figure 10(c)). Positive phase of the PDO induces positive wind stress anomaly in the Yellow Sea (Figures 9, 10(c) and Table 4). Due to the shallow depth of the Yellow Sea, a stronger wind stress can strengthen mixing, which produces a smaller A-YSCWM (Figure 11(c) and Table 3 ).

The correlations between MEI and A-YSCWM and TYSCWM are -0.41 and 0.32 , respectively (Figure $8(\mathrm{a})$ and Table 1). From 1976 to 2006, the MEI represents the warm ENSO phase. The corresponding T-YSCWM (A-YSCWM) is a positive (negative) anomaly. However, the correlations 

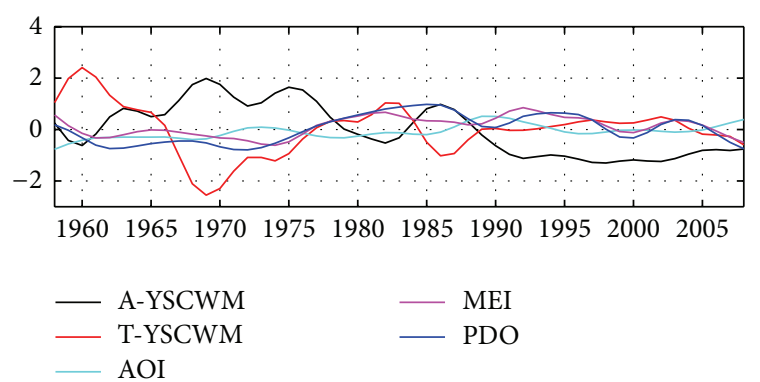

(a)

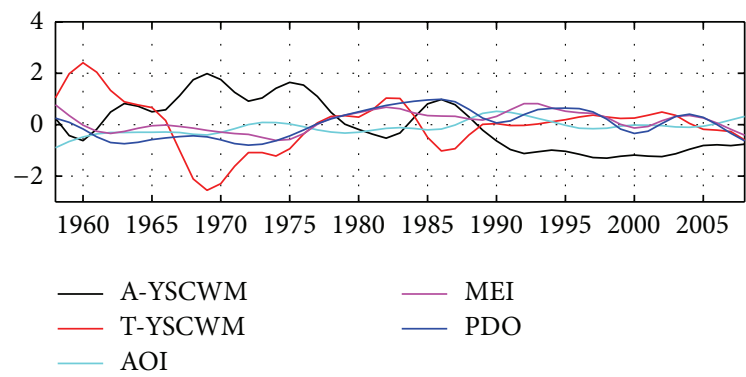

(b)

FIGURE 8: Decadal time series of (a) winter AO, MEI, and PDO index, and the A-YSCWM and T-YSCWM in August (b) summer $\mathrm{AO}, \mathrm{MEI}$, and PDO index, and the A-YSCWM and T-YSCWM in August. Time series of the A-YSCWM and T-YSCWM are standardized. The A-YSCWM and T-YSCWM represent the area and averaged temperature of the YSCWM, respectively.

TABLE 2: Correlation coefficients between EOF1, EOF2, and EOF3 of heat flux and A-YSCWM, T-YSCWM in August, including the interannual and decadal components in both summer and winter. Bold texts indicate that the correlations are statistically significant at the $95 \%$ confidence level.

\begin{tabular}{lcc}
\hline & A-YSCWM & T-YSCWM \\
\hline \multicolumn{4}{c}{ Interannual variability } \\
EOF1 of winter heat flux & $-\mathbf{0 . 3 2}$ & $\mathbf{0 . 3 7}$ \\
EOF2 of winter heat flux & -0.16 & 0.14 \\
EOF3 of winter heat flux & 0.04 & -0.08 \\
EOF1 of summer heat flux & -0.13 & 0.07 \\
EOF2 of summer heat flux & 0.04 & 0.03 \\
EOF3 of summer heat flux & 0.17 & 0.01 \\
\hline \multicolumn{1}{c}{ Decadal variability } \\
EOF1 of winter heat flux & $\mathbf{0 . 7 4}$ & -0.08 \\
EOF2 of winter heat flux & 0.02 & $-\mathbf{0 . 3 3}$ \\
EOF3 of winter heat flux & 0.02 & $-\mathbf{0 . 3 9}$ \\
EOF1 of summer heat flux & $\mathbf{0 . 5 9}$ & $-\mathbf{0 . 6 4}$ \\
EOF2 of summer heat flux & $-\mathbf{0 . 5 6}$ & -0.11 \\
EOF3 of summer heat flux & 0.22 & -0.12 \\
\hline
\end{tabular}

between MEI and local wind stress and heat flux are low (Figures 10(a), 10(c) and Table 4). The results indicate that the winter ENSO event is strongly linked to the decadal variability of the YSCWM, but not through changes in wind stress and heat fluxes.
TABLE 3: Correlation coefficients between EOF1, EOF2, and EOF3 of wind stress and A-YSCWM, T-YSCWM in August, including the interannual and decadal components in both summer and winter. Bold texts indicate that the correlations are statistically significant at the $95 \%$ confidence level.

\begin{tabular}{lcc}
\hline & A-YSCWM & T-YSCWM \\
\hline \multicolumn{1}{c}{ Interannual variability } \\
EOF1 of winter wind stress & $-\mathbf{0 . 3 3}$ & $\mathbf{0 . 3 3}$ \\
EOF2 of winter wind stress & 0.08 & -0.09 \\
EOF3 of winter wind stress & $-\mathbf{0 . 3 1}$ & $\mathbf{0 . 2 7}$ \\
EOF1 of summer wind stress & -0.07 & 0.11 \\
EOF2 of summer wind stress & 0.15 & -0.07 \\
EOF3 of summer wind stress & -0.08 & 0.12 \\
\hline \multicolumn{1}{c}{ Decadal variability } \\
EOF1 of winter wind stress & -0.13 & \\
EOF2 of winter wind stress & $-\mathbf{0 . 5 6}$ & -0.23 \\
EOF3 of winter wind stress & $\mathbf{0 . 3 1}$ & $\mathbf{0 . 7 5}$ \\
EOF1 of summer wind stress & 0.19 & 0.08 \\
EOF2 of summer wind stress & -0.19 & $\mathbf{0 . 5 6}$ \\
EOF3 of summer wind stress & $-\mathbf{0 . 3 9}$ & 0.14 \\
\hline
\end{tabular}

4.2.2. Relationship to Climate Forcings in Summer. On the decadal time scale, the A-YSCWM is negatively correlated with the summer AO index, with a correlation coefficient of -0.30 (Figure 8(b) and Table 1). The A-YSCWM and the summer MEI are negatively correlated with a coefficient of -0.60 (Figure 8(b) and Table 1). The correlation between T-YSCWM and summer MEI is positive with the correlation coefficient of 0.38 (Figure 8 (b) and Table 1). On a decadal time scale, the summer MEI during 1966-1978 is in its negative phase while the anomaly in A-YSCWM (TYSCWM) is positive (negative). After 1978, the summer MEI is in its positive phase (Figure $8(\mathrm{~b})$ ). Correspondingly, the A-YSCWM (T-YSCWM) anomaly is negative (positive). However, when PDO turns to a weak signal in summer, the correlation between the PDO and the YSCWM becomes not significant (Figure $8(\mathrm{~b})$ and Table 1 ).

The summer AO and MEI may affect both EOF2 and EOF3 of the summer heat flux and EOF1 of summer wind stress, modulating the decadal variability of the YSCWM (Figures 10(b), 10(d) and Table 5). However, because of the low correlation between the EOF2 of the summer heat flux and the decadal variability of the YSCWM, AO and MEI may not affect the decadal variability of the YSCWM through changes in the EOF2 of the summer heat flux (Table 3). The summer AO and ENSO indices are negatively correlated with EOF3 of summer heat flux and EOF1 of summer wind stress (Table 5). When the summer AO and ENSO are in their positive phases, the heat flux from the atmosphere into the ocean is enhanced (Figures 9, 10 and Table 5). Therefore, the A-YSCWM decreases, and the T-YSCWM increases (Figure 11 and Table 3).

\section{Summary}

We use the CORA reanalysis data to investigate the lowfrequency variability of the YSCWM. First, we examine the 


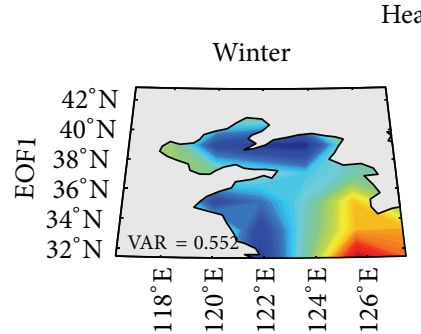

(a)

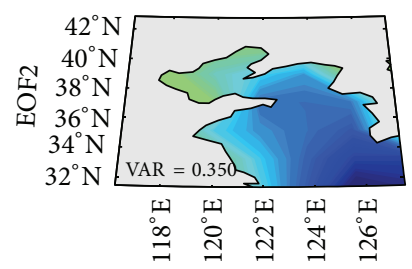

(e)

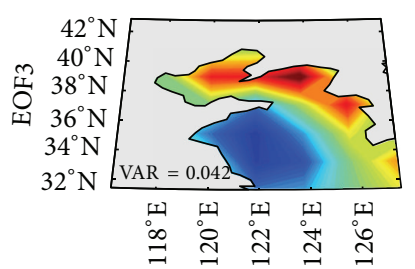

(i)
Heat flux

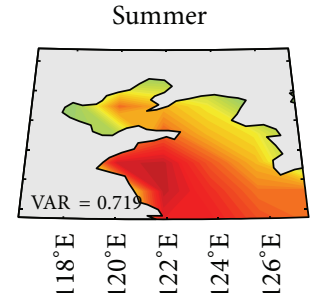

(b)

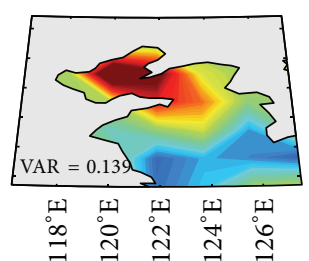

(f)

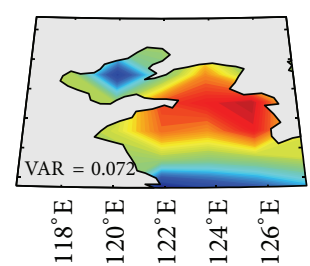

(j)

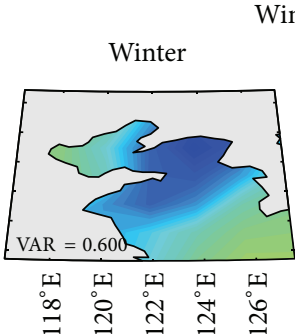

(c)

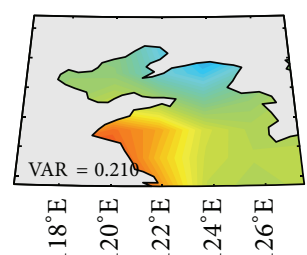

(g)

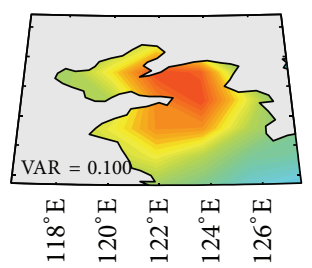

(k)
Wind stress

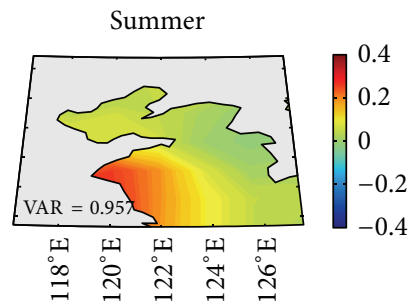

(d)

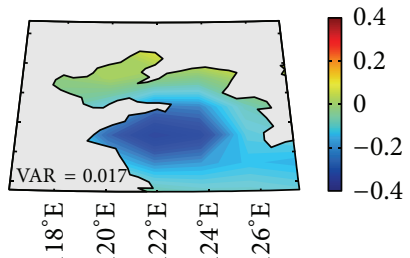

(h)

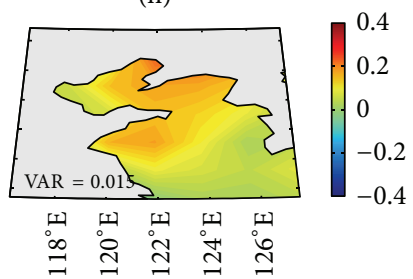

(l)

FIGURE 9: EOF1, EOF2, and EOF3 of decadal components for winter heat flux ((a), (e), and (i)) and summer heat flux ((b), (f), and (g)), winter wind stress $((\mathrm{c}),(\mathrm{g})$, and $(\mathrm{k}))$, and summer wind stress $((\mathrm{d}),(\mathrm{h})$, and $(\mathrm{l}))$. Positive values indicate that heat is transferred from the ocean to the atmosphere.

TABLE 4: Correlation coefficients between EOF1, EOF2, and EOF3 of winter heat flux, wind stress, and winter AO, ENSO, and PDO, including the interannual and decadal components. Bold texts indicate that the correlations are statistically significant at the $95 \%$ confidence level.

\begin{tabular}{|c|c|c|c|c|}
\hline & & Winter $\mathrm{AO}$ & Winter MEI & Winter PDO \\
\hline \multirow{6}{*}{ Interannual variability } & EOF1 of winter heat flux & 0.26 & 0.02 & -0.11 \\
\hline & EOF2 of winter heat flux & -0.08 & 0.10 & -0.11 \\
\hline & EOF3 of winter heat flux & 0.47 & 0 & -0.03 \\
\hline & EOF1 of winter wind stress & 0.09 & 0.09 & -0.01 \\
\hline & EOF2 of winter wind stress & 0.10 & -0.05 & -0.04 \\
\hline & EOF3 of winter wind stress & 0.04 & 0.17 & -0.11 \\
\hline \multirow{6}{*}{ Decadal variability } & EOF1 of winter heat flux & -0.59 & -0.12 & -0.47 \\
\hline & EOF2 of winter heat flux & -0.09 & -0.06 & 0.13 \\
\hline & EOF3 of winter heat flux & 0.57 & 0.08 & -0.31 \\
\hline & EOF1 of winter wind stress & 0.17 & -0.04 & -0.10 \\
\hline & EOF2 of winter wind stress & -0.21 & 0.25 & 0.33 \\
\hline & EOF3 of winter wind stress & -0.14 & -0.12 & -0.77 \\
\hline
\end{tabular}

formation and evolution of the YSCWM on the seasonal scale. The YSCWM forms in spring and reaches its maximum extension in summer. Since the early fall, the area occupied by the YSCWM starts to decrease. In December, the YSCWM disappears. The evolution process of the YSCWM derived from CORA is consistent with the evolution showed by the observations as described in previous studies [24].
Next, we examine the interannual and decadal variability of the YSCWM and its association with the climate forcing including AO, ENSO, and PDO. The climate forcing plays an important role in modulating the YSCWM variability. For the interannual variability of the YSCWM, the correlation between the winter PDO and the YSCWM is the strongest among the three climate indices, which indicates that the 


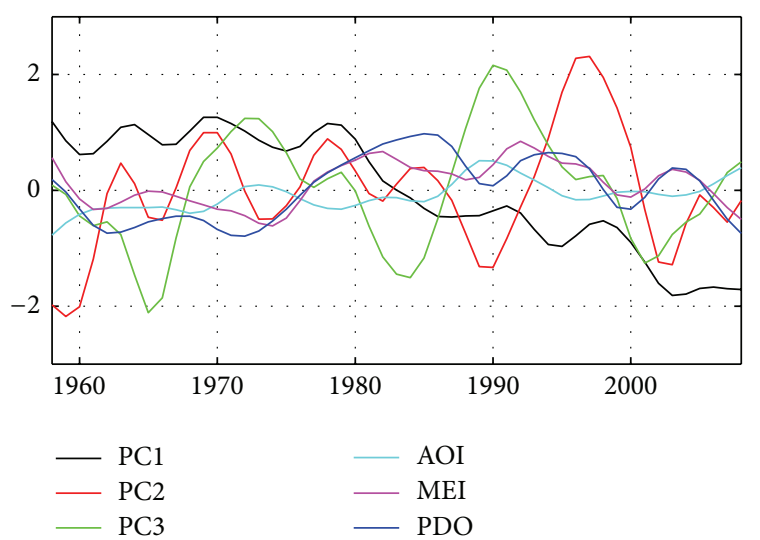

(a)

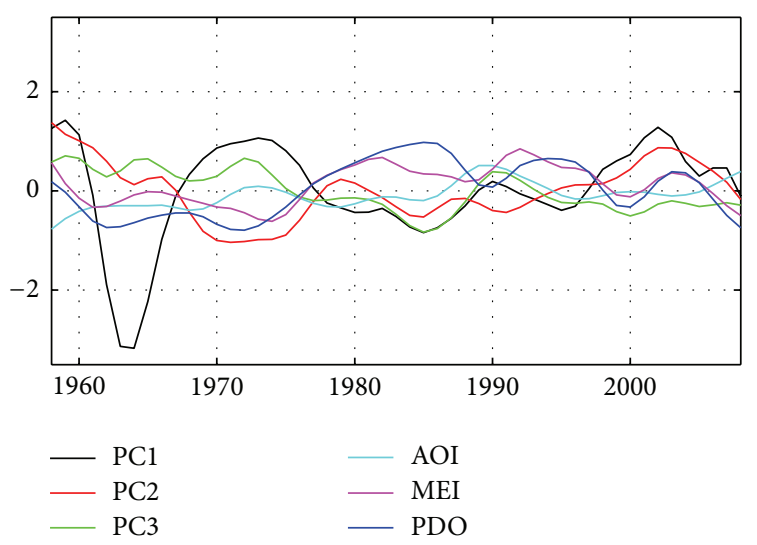

(c)

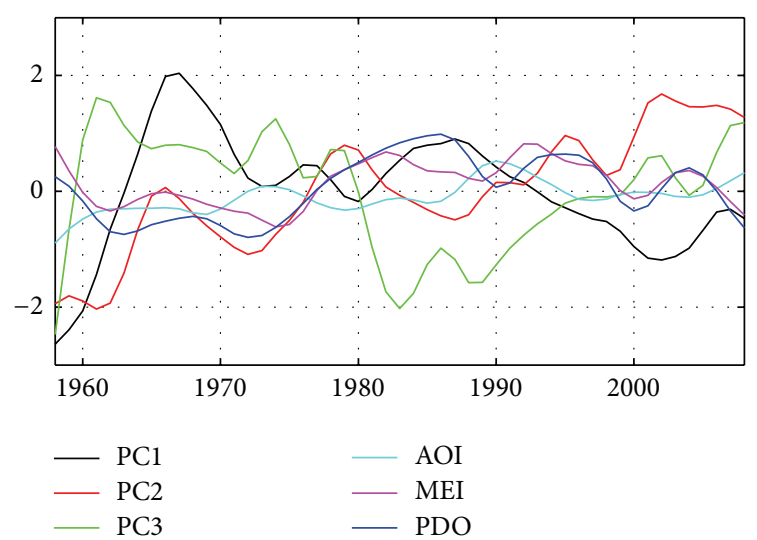

(b)

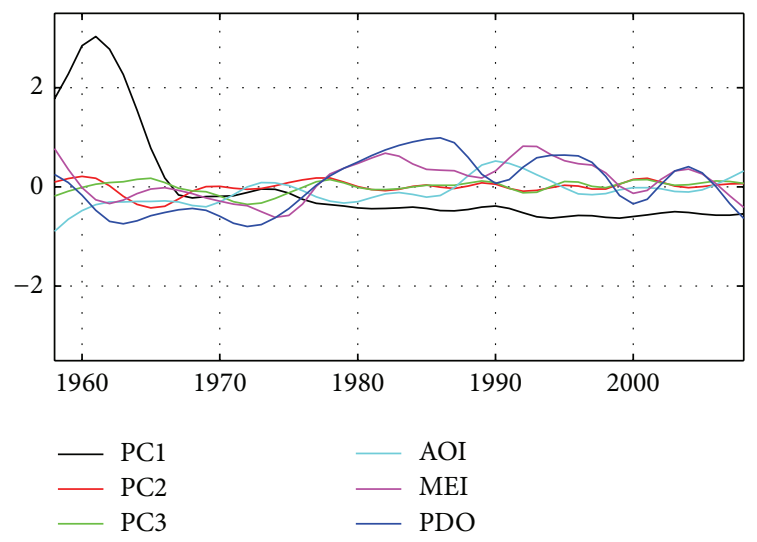

(d)

FIGURE 10: Decadal time series of (a) winter AO, MEI, PDO, EOF1, EOF2, and EOF3 of winter heat flux; (b) summer AO, MEI, PDO, EOF1, EOF2, and EOF3 of heat flux; (c) winter AO, MEI, PDO, and EOF1, EOF2, and EOF3 of winter wind stress; (d) summer AO, MEI, PDO, and $\mathrm{EOF} 1$, and EOF2 and EOF3 of summer wind stress. EOF1, EOF2, and EOF3 of heat flux and wind stress are standardized.

TABLE 5: Correlation coefficients between EOF1, EOF2, and EOF3 of summer heat flux, wind stress, and winter AO, ENSO, and PDO, including the interannual and decadal components. Bold texts indicate that the correlations are statistically significant at the $95 \%$ confidence level.

\begin{tabular}{|c|c|c|c|c|}
\hline & & Summer AO & Summer MEI & Summer PDO \\
\hline \multirow{6}{*}{ Interannual variability } & EOF1 of summer heat flux & -0.07 & 0.01 & 0.01 \\
\hline & EOF2 of summer heat flux & 0.04 & 0.09 & 0.13 \\
\hline & EOF3 of summer heat flux & -0.01 & 0.17 & 0.12 \\
\hline & EOF1 of summer wind stress & 0.01 & 0.01 & -0.05 \\
\hline & EOF2 of summer wind stress & -0.04 & 0.11 & 0.12 \\
\hline & EOF3 of summer wind stress & -0.01 & 0.11 & 0.15 \\
\hline \multirow{6}{*}{ Decadal variability } & EOF1 of summer heat flux & 0.08 & -0.13 & 0.14 \\
\hline & EOF2 of summer heat flux & 0.41 & 0.47 & 0.26 \\
\hline & EOF3 of summer heat flux & -0.40 & -0.61 & -0.79 \\
\hline & EOF1 of summer wind stress & -0.57 & -0.36 & -0.48 \\
\hline & EOF2 of summer wind stress & 0.15 & -0.07 & -0.03 \\
\hline & EOF3 of summer wind stress & -0.02 & 0.31 & 0.04 \\
\hline
\end{tabular}

effect of the winter PDO on the YSCWM is dominant. In this study, we do not investigate how PDO modulate the Yellow Sea circulation to influence the YSCWM. Previous studies suggested that the signal of PDO can be transferred into the Yellow Sea through Kuroshio and therefore affect the circulation of the Yellow Sea [16, 25]. It was also suggested that Yellow Sea warm current can influence the variability of the YSCMW [26]. It is necessary to further investigate in a future study how PDO influences the Yellow Sea circulation and modulates the YSCWM. It is also found that the local 


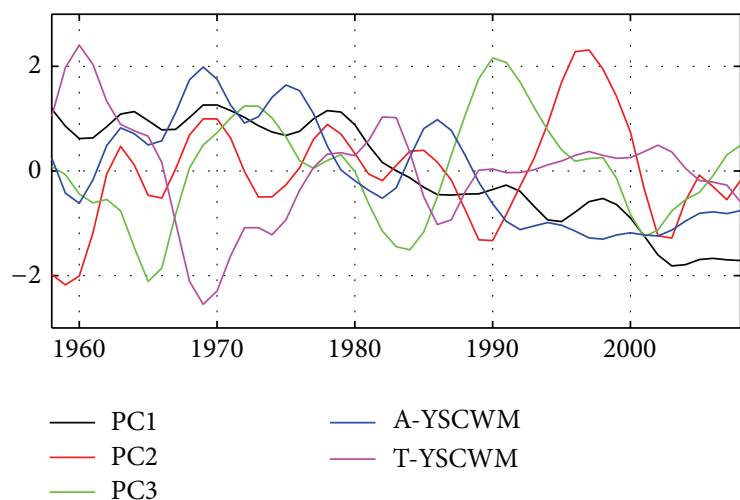

(a)

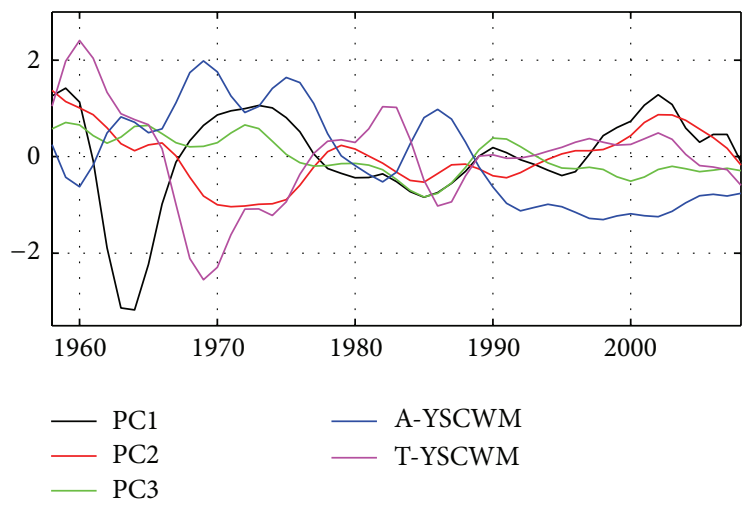

(c)

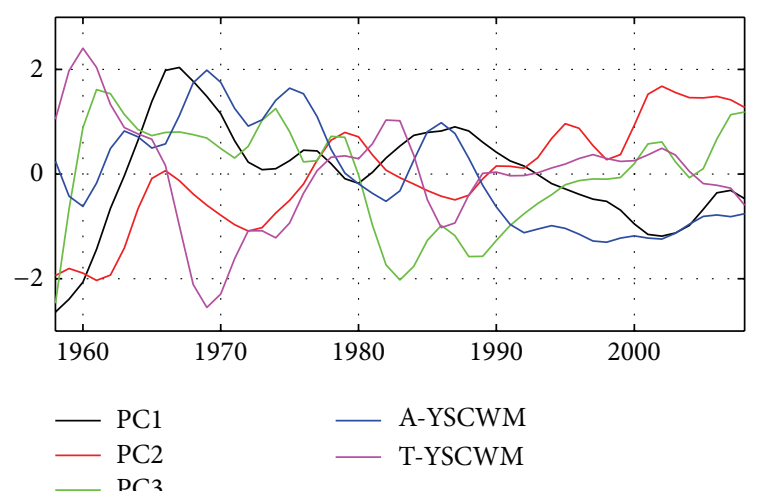

(b)

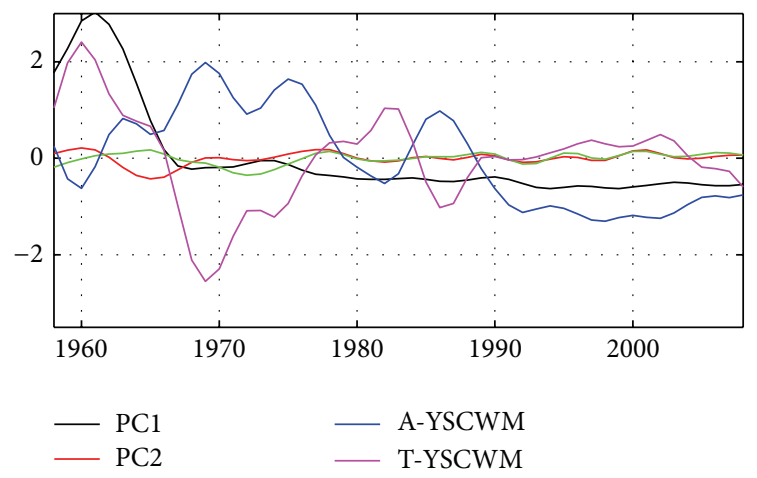

(d)

FIGURE 11: Decadal time series of (a) EOF1, EOF2, and EOF3 of winter heat flux, and the A-YSCWM and T-YSCWM in August (b) EOF1, EOF2, and EOF3 of summer heat flux, and the A-YSCWM and T-YSCWM in August (c) EOF1, EOF2, and EOF3 of winter wind stress, and the A-YSCWM and T-YSCWM in August (d) EOF1, EOF2, and EOF3 of summer wind stress, and the A-YSCWM and T-YSCWM in August. All of the time series are standardized. The A-YSCWM and T-YSCWM represent the area and averaged temperature of the YSCWM, respectively.

wind stress and heat flux in summer have little influence on the variability of the YSCWM. In summer, no correlation is found between the climate indices and the local heat flux and wind stress. This suggests that the AO, ENSO, and PDO may not affect the interannual variability of the YSCWM through modulating the local heat flux and wind stress in summer.

For the decadal variability of the YSCWM, the negative correlations between the winter $\mathrm{AO}, \mathrm{PDO}$, and the area of the YSCWM are significant. The winter AO mainly controls the first mode of heat flux to modulate the decadal variability of the YSCWM. When the winter AO is in its positive phase, the heat flux from atmosphere to ocean in the northwestern Yellow Sea is abnormally high. The average temperature of the YSCWM also increases accordingly. The winter PDO is strongly connected to the first mode of winter heat flux. When the winter PDO is in its positive phase, the increase of heat flux from atmosphere to ocean in the Yellow Sea can reduce the area of the YSCWM. At the same time, the winter PDO has positive correlation with the sea surface pressure. Along with the PDO enhanced, the enhancement of sea surface pressure is in conformity with wind speed. The positive PDO can induce positive wind stress anomaly in the Yellow Sea through the modulation of the EOF2 and EOF3. Due to the shallow depth of the Yellow Sea, the strong wind stress and the enhanced sea surface pressure can strengthen mixing, reducing the area of the YSCWM. The correlation between winter MEI and the YSCWM is significant, suggesting a link with decadal variability of the YSCWM. However, this relationship cannot be explained by changes in the wind stress and heat fluxes. In summer, ENSO has the strongest influence on the YSCWM variability. ENSO may exert influence on the third mode of summer heat flux and the first mode of summer wind stress to modulate the decadal variability of the YSCWM.

\section{Conflict of Interests}

The authors declare that there is no conflict of interests regarding the publication of this paper.

\section{Acknowledgments}

This study is supported by the National Basic Research Program of China (2013CB430304), National Natural Science Foundation of China (41106005, 41176003, 41206178, 41376015, 41376013, 41306006, and 41276015), National HighTech R\&D Program (2013AA09A505) of China, and Global 
Change and Air-Sea Interaction (GASI-01-01-12). Peter C. Chu is supported by the Naval Oceanographic Office. The Arctic Oscillation, Multivariate ENSO, and Pacific Decadal Oscillation indices are downloaded from the websites: http://www.cpc.ncep.noaa.gov/, http://www.cdc.noaa.gov/, and http://jisao.washington.edu/pdo, respectively.

\section{References}

[1] Q. Tang, X. Jin, J. Wang, Z. Zhuang, Y. Cui, and T. Meng, "Decadal-scale variations of ecosystem productivity and control mechanisms in the Bohai Sea," Fisheries Oceanography, vol. 12, no. 4-5, pp. 223-233, 2003.

[2] C. Yongli, H. Dunxin, and W. Fan, "Long-term variabilities of thermodynamic structure of the East China Sea Cold Eddy in summer," Chinese Journal of Oceanology and Limnology, vol. 22, no. 3, pp. 224-230, 2004.

[3] S. W. Zhang, C. S. Xia, and Y. L. Yuan, "A physical-biochemical coupling model of Yellow Sea cold water mass," Progress in Natural Science, vol. 12, pp. 315-320, 2002.

[4] H.-J. Lie, C.-H. Cho, J.-H. Lee, S. Lee, Y. Tang, and E. Zou, "Does the yellow sea warm current really exist as a persistent mean flow?" Journal of Geophysical Research C: Oceans, vol. 106, no. 10, pp. 22199-22210, 2001.

[5] H. B. Hur, G. A. Jacobs, and W. J. Teague, "Monthly water mass analyses in the Yellow and East China Seas," Journal of Oceanography, vol. 55, pp. 171-184, 1999.

[6] C. B. He, Y. X. Wang, Z. Y. Lei, and S. Xu, "A preliminary study of the formation and its properties of the Yellow Sea Cold Water Mass," Oceanologia et Limnologia Sinica, vol. 2, pp. 11-15, 1959.

[7] Y. S. Su, "A survey of geographical environment, circulation systems and the central fishing grounds in the Huanghai Sea and East China Sea," Journal of Shandong College of Oceanology, vol. 16, no. 1, pp. 12-27, 1986.

[8] S.-L. Wang and C.-T. A. Chen, "Bottom water at the center of the north east china sea in summer: remnant winter water," Continental Shelf Research, vol. 18, no. 13, pp. 1573-1580, 1998.

[9] J. L. Su and D. J. Huang, "On the current field associated with the Yellow Sea cold water mass," Oceanologia et Limnologia Sinica Supplement, vol. 26, no. 5, pp. 1-7, 1995.

[10] J. B. Miu and X. Q. Liu, “The preliminary discussion about the formation mechanism of the north Yellow Sea cold water massI.model solution," Scientia Sinica Series B, vol. 1, pp. 1311-1321, 1990.

[11] J. B. Miu and X. Q. Liu, "The preliminary discussion about the formation mechanism of the north Yellow Sea cold water massII. Discussion of the model solution," Scientia Sinica, Series B, vol. 2, pp. 74-81, 1991.

[12] H. Q. Li and Y. L. Yuan, "Theoretical study on the thermal structure and circulation pattern related to cold water mass of Yellow Sea," Oceanologia et Limnologia Sinica, vol. 23, no. 1, pp. 7-13, 1992.

[13] H. J. Ren and J. M. Zhan, "A numerical study on the seasonal variability of the Yellow Sea cold water mass and the related dynamics," Journal of Hydrodynamics A, vol. 20, supplement, pp. 887-896, 2005.

[14] B. J. Jiang, X. W. Bao, D. X. Wu, and J. P. Xu, "Interannual variation of temperature and salinity of northern Huanghai Sea Cold Water Mass and its probable cause," Acta Oceanologica Sinica, vol. 29, no. 4, pp. 1-10, 2007.
[15] D. X. Hu and Q. Y. Wang, "Interannual variability of the southern Yellow Sea Cold Water Mass," Chinese Journal of Oceanology and Limnology, vol. 22, no. 3, pp. 231-236, 2004.

[16] S. Park, P. C. Chu, and J.-H. Lee, "Interannual-to-interdecadal variability of the Yellow Sea Cold Water Mass in 1967-2008: characteristics and seasonal forcings," Journal of Marine Systems, vol. 87, no. 3-4, pp. 177-193, 2011.

[17] G. Han, W. Li, X. Zhang et al., "A regional ocean reanalysis system for coastal waters of China and adjacent seas," Advances in Atmospheric Sciences, vol. 28, no. 3, pp. 682-690, 2011.

[18] D. W. J. Thompson and J. M. Wallace, "The Arctic oscillation signature in the wintertime geopotential height and temperature fields," Geophysical Research Letters, vol. 25, no. 9, pp. 12971300, 1998.

[19] K. Wolter and M. S. Timlin, "Monitoring ENSO in COADS with a seasonally adjusted principal component index," in Proceedings of the 17th Climate Diagnostics Workshop, pp. 52-57, Climate Analysis Center, National Oceanic and Atmospheric Administration (NOAA), Norman, Okla, USA, 1993.

[20] K. Wolter and M. S. Timlin, "Measuring the strength of ENSO events: how does 1997/98 rank?” Weather, vol. 53, no. 9, pp. 315324, 1998.

[21] Y. Zhang, J. M. Wallace, and D. S. Battisti, "ENSO-like interdecadal variability: 1900-93," Journal of Climate, vol. 10, no. 5, pp. 1004-1020, 1997.

[22] N. J. Mantua, S. R. Hare, Y. Zhang, J. M. Wallace, and R. C. Francis, "A Pacific Interdecadal Climate Oscillation with Impacts on Salmon Production," Bulletin of the American Meteorological Society, vol. 78, no. 6, pp. 1069-1079, 1997.

[23] E. Kalnay, M. Kanamitsu, R. Kistler et al., "The NCEP/NCAR 40-year reanalysis project," Bulletin of the American Meteorological Society, vol. 77, no. 3, pp. 437-471, 1996.

[24] S. W. Zhang, Q. Y. Wang, Y. Lü, H. Cui, and Y. L. Yuan, “Observation of the seasonal evolution of the Yellow Sea Cold Water Mass in 1996-1998," Continental Shelf Research, vol. 28, no. 3, pp. 442-457, 2008.

[25] A. L. Gordon and C. F. Giulivi, "Pacific decadal oscillation and sea level in the Japan/East sea," Deep Sea Research Part I: Oceanographic Research Papers, vol. 51, no. 5, pp. 653-663, 2004.

[26] H.-J. Lie, C.-H. Cho, J.-H. Lee, S. Lee, Y. Tang, and E. Zou, “Does the Yellow Sea Warm Current really exist as a persistent mean flow?" Journal of Geophysical Research C: Oceans, vol. 106, no. 10, pp. 22199-22210, 2001. 

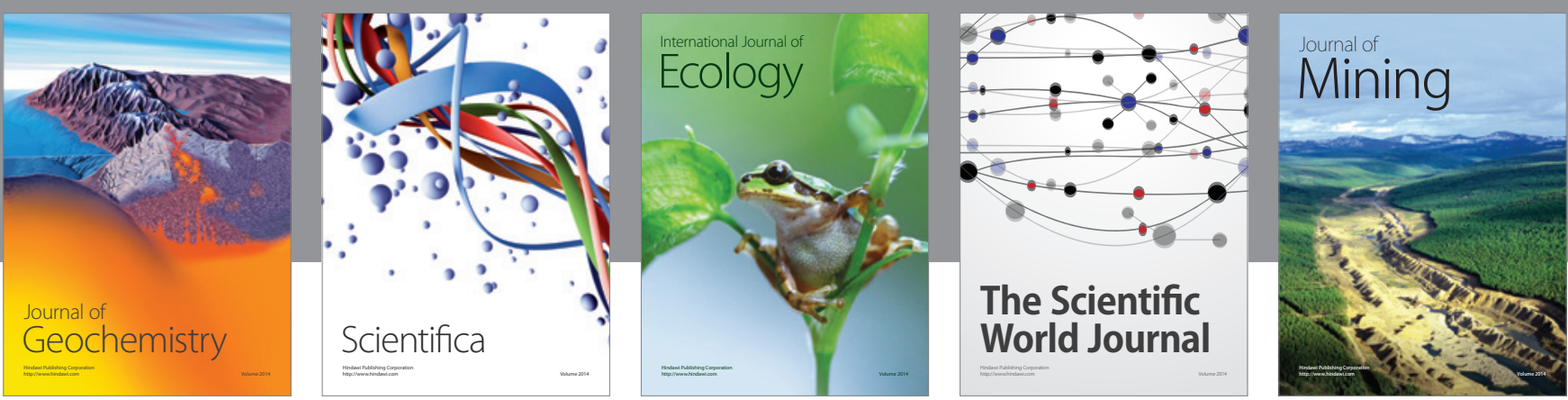

The Scientific World Journal
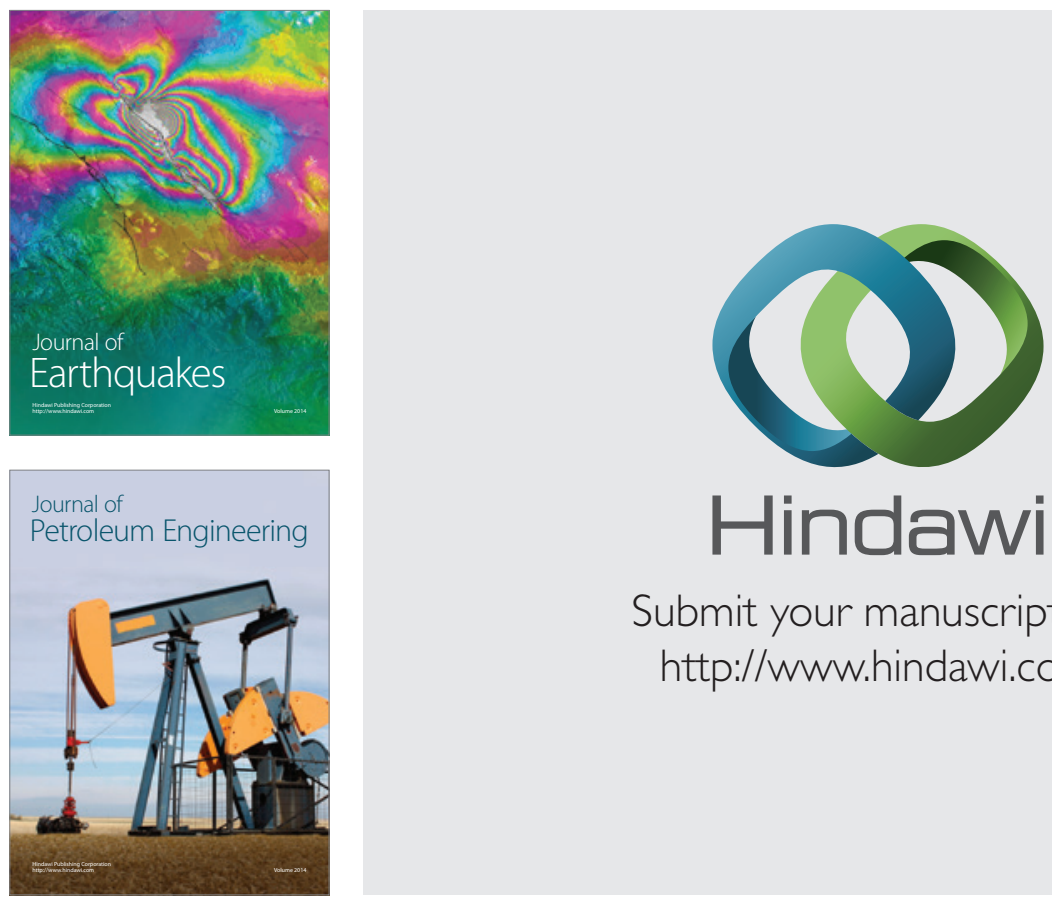

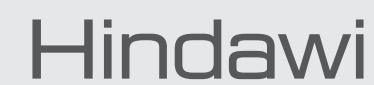

Submit your manuscripts at

http://www.hindawi.com
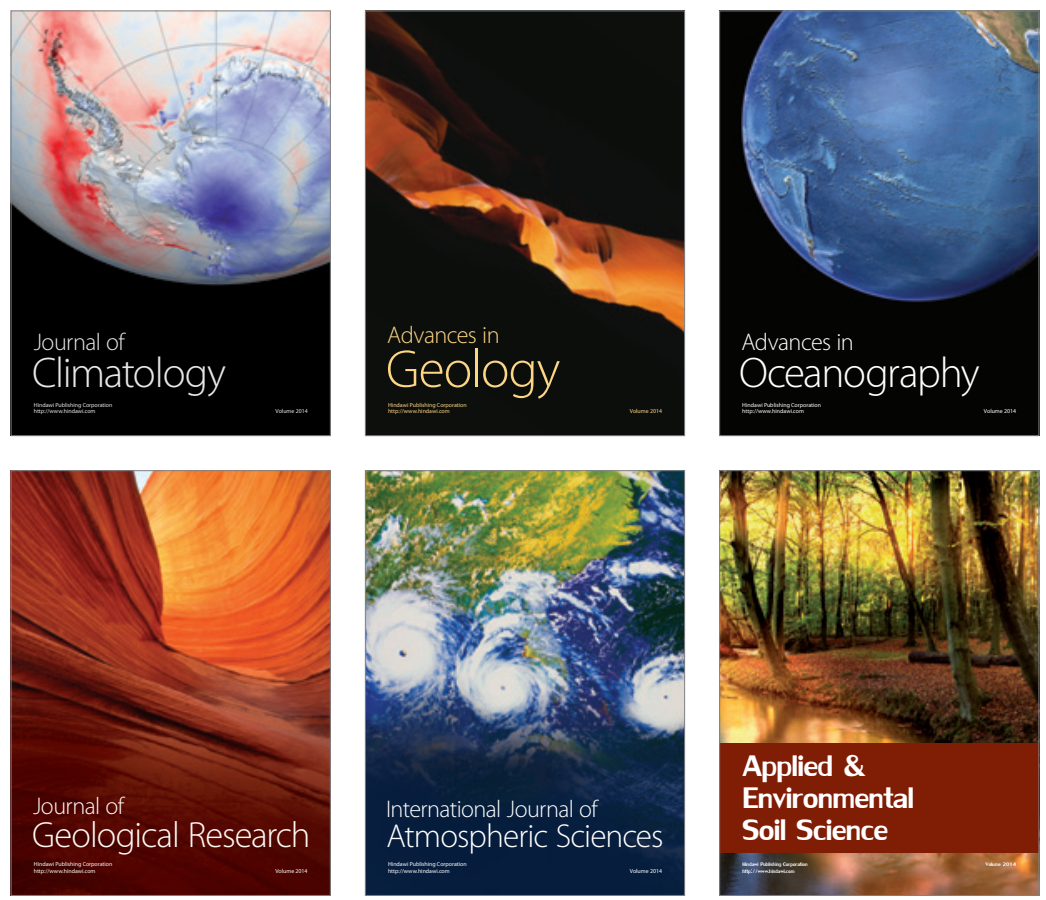
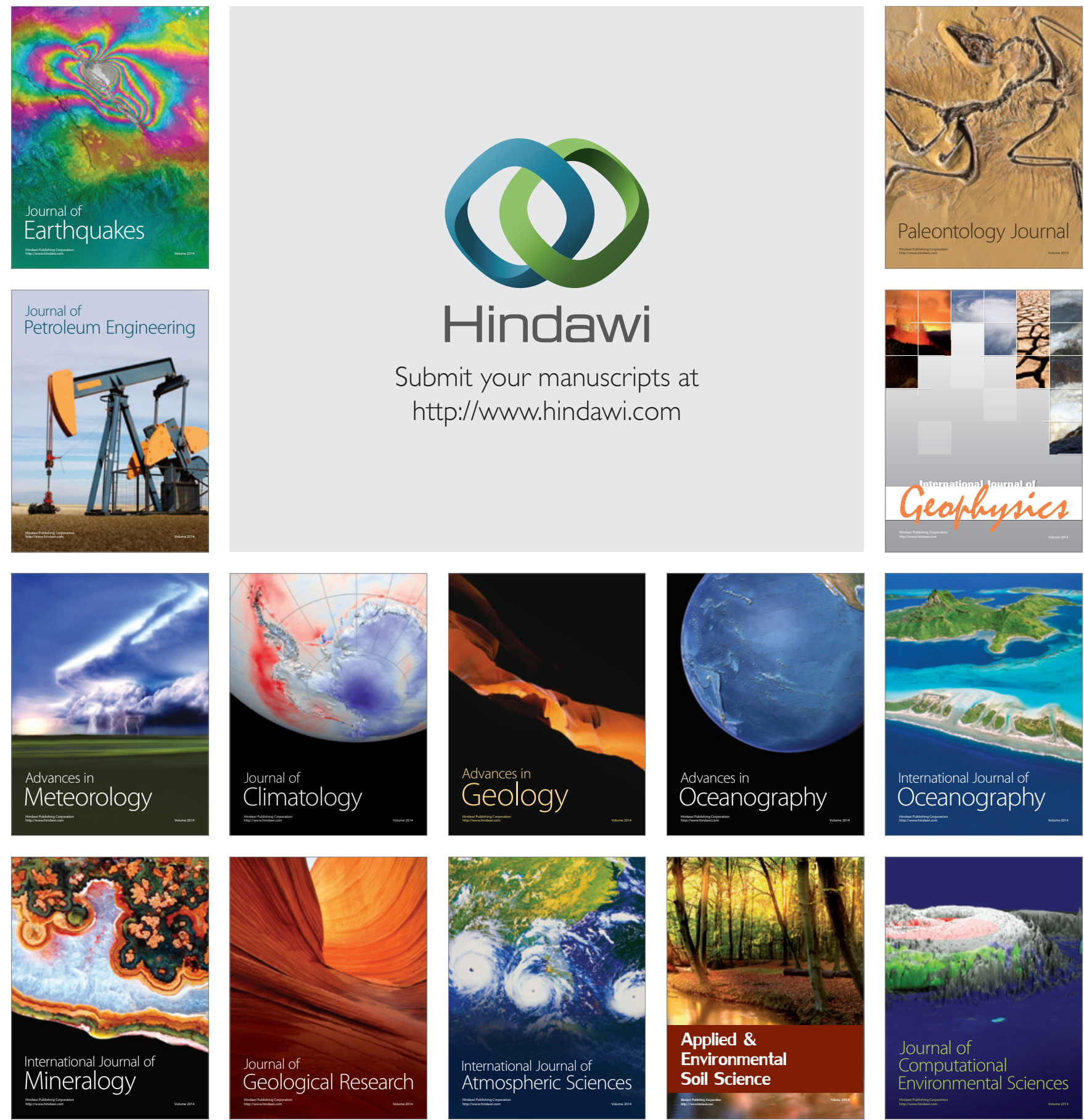